\title{
Bactérias enteropatogênicas de diarréia infantil aguda em Tucuruí, Pará (1)
}

\author{
Jurandir Chaves de Vasconcelos $\left.{ }^{2}\right]$
}

\begin{abstract}
Resumo
Foram efetuados exames bacteriológico e parasi tológico de fezes de 110 crianças diarréicas na faixa etária de 0-10 anos, atendidas em 2 (dois) hospitais de Tucurui, Pará. As amostras foram examinadas antes de qualquer tratamento médico. Em 51 casos $(46,3 \%)$ foram identificados bactérias e/ou parasitas intestinais, sendo 17 casos $(15,4 \%)$ bactérias, 28 casos $(25,4 \%)$ parasitas e 6 casos $(5,4 \%)$ bactérias e parasitas. Patogenos bacterianos foram isolados em 23 amostras $(20,9 \%)$ : 21 Escherichia coli sorogrupos patogênicos, 1 Shigella sonnei e 1 Shigella flexneri. Oito sorogrupos diferentes de $\mathbf{E}$. coli foram identificados. O sorogrupo de maior frequiência foi o $026 \mathrm{~K} 60$ seguido pelo 086a:K61. Todas as cepas patogênicas com exceção da E. coli 0119:K69 apresentaram resistência múltipla frente a 12 drogas antimicrobianas. Foram os seguintes os parasitas intestinais identificados: Giardia lamblia $15,4 \%$, Ascaris lumbricoides $10,0 \%$, Entamoeba histolytica $6,3 \%$, Strongyloides stercoralis $4,5 \%$, Trichocephalus trichiurus $2,7 \%$, Ancilostoma sp $1,8 \%$, Taenia sp $0,9 \%$, Balantidium coli $0,9 \%$ e Himenolepis nana $0,9 \%$.
\end{abstract}

\section{INTRODUÇÃo}

A $300 \mathrm{~km}$ em linha reta de Belém, está localizada a cidade de Tucuruí. Situada à margem esquerda do rio Tocantins, em sua bacia está sendo construída, sob a responsabilidade da ELETRONORTE, a Usina Hidrelétrica Tucuruí que, após sua conclusão, será a quarta maior do mundo e a maior genuinamente brasileira.

A regiāo de Tucuruí, por força da construção da Hidrelétrica, foi subdividida em quatro partes: cidade de Tucuruí, Vila Pioneira, Vila Temporária (I e II) e Vila Permanente.

A cidade, cuja administração é de responsabilidade do Governo Estadual, corresponde ao local onde existe o maior aglomerado de casas $\bullet$ onde as condições higiênico-sanitárias, de um modo gera!, são precárias.
Já os núcleos sob a responsabilidade da ELETRONORTE contam com toda a infra-estrutura de águas, esgotos, rede elétrica, coleta de lixo etc.

A Vila Pioneira dispõe da infra-estrutura mencionada, mas ainda pode sofrer ocasionalmente alguma influência da cidade de Tucuruí, devido à sua localização, próxima à cidade.

A Vila Temporária, dividida em I e II, é formada por casas pré-fabricadas, construídas nas proximidades da barragem com o objetivo de atender aos familiares dos trabalhadores aa Usina. A Vila Temporária II terá uma parte inundacia quando da construção do canal da eclusa de transposição da barragem da UHE TUCURUI.

A última parte, a Vila Permanente, foi construída para abrigar os responsáveis pela operação e manutenção da Usina. É a que oferece as meihores condições de habitação, sendo considerada a melhor infra-estrutura urbana de todo o Norte do Brsisil. O local é totalmente urbanizado e conta com ruas asfaltadas. As casas, feitas em alvenaria, oferecem o conforto compativel às das melhores residências urbanas a seus habitantes e poderão servir de parâmetros às novas edificações que porventura venham a ser necessárias.

O crescimento demográfico da localidade de Tucuruí está se processando de maneira acelerada, haja visto que, conforme dados numéricos disponiveis, em 1974 havia apenas 800 habitantes, enquanto em 1979 este númєro já atingia cerca de $30 \mathrm{mil}$ habitantes. Isto se deve à construção da Hidrelétrica, que veio abrir frentes de trabalho para muita gente, numa região que, antes, não oferecia grandes perspectivas neste aspecto.

(1) - Este trabalho foi realizado com apoio do Conselho Nacional de Desenvolvimento Científico e Tecnológico (CNPq) através do Convênio entre o Instituto Naşional de Pesquisas da Amazônia e ELETRONORTE no Projeto Tucuruí.

(2) - Instituto Nacional de Pesquisas da Amazônia, Manaus. 
$\mathrm{O}$ crescimento populacional, aliado à migração de operários, principalmente do Norte e do Nordeste, veio trazer uma preocupação para a ELETRONORTE no combate das doenças, em especial as gastrointestinais, que ainda representam a maior causa de morbidade e mortalidade infantil.

O objetivo principal do nosso estudo foi o de determinar os agentes etiológicos das diarréias agudas em crianças atendidas em dois hospitais local, pois, segundo Du Pont (1975), para se reduzir ao mínimo a mortalidade e a morbidade por infecçōes entéricas faz necessário obter-se informações sobre três pontos principais: a etiologia da diarréia aguda, os aspectos nutricionais das infecções entéricas e as incógnitas sobre os problemas e recursos de cadá regiảo.

\section{MATERIAL E MÉtodos}

Os trabalhos preliminares foram desenvoividos no período compreendido entre julho e setembro de 1980, em dois hospitais em Tucurui: Hespital da Vila Temporária (Construtora Camargo Correa) e Hospital da SESPA (Secretaria de Estado de Saúde do Pará em Tucuruí) e mais tarde no Laboratório de Bacteriologia do INPA.

Nos referidos hospitais tivemos o apoio do corpo pediátrico e também do pessoal que trabalhava em seus Laboratórios.

Um total de 110 (cento e dez) crianças na faixa etária entre $0-10$ anos com episódio de diarréia aguda, foi atendido clinicamente e coletadas as suas fezes, nos próprios hospitais, arites de qualquer tratamento médico.

\section{COLETA DE AMOSTRAS}

As amostras fecais foram coletadas em frascos plásticos de boca larga e logo em seguida processadas para os exames parasitológico e bacteriológico. Parte das amostras também foram congeladas para pesquisa posterior de Rotavirus através de Microscopia eletrônica e contraimunoeletroforese no INPA, trabalho que será publicado posteriormente.

\section{EXAME BACTERIOLÓGICO DAS FEZES}

Logo após a sua coleta, as fezes foram semeadas em MacConkey Agar, Salmonella -. Shigella Agar (SS A.gar), Hektoen Enteric Agar e Tetrathionate Broth. As colônias bacterianas com características de Escherichia coli, Salmonella e Shigella foram conservadas em Agar nutriente e estocadas para a sua identificação posterior. Os métodos de identificação bioquímica e sorológica dos germes isolados foram os recomendados por (Edwards \& Ewing, 1975) e efetuados no Laboratório de Bacteriologia do INPA.

\section{EXAME PARASITOLÓGICO DAS FEZES}

As amostras de fezes foram examinadas para estudo parasitológico através do método direto com e sem lugol, para evidenciação de formas císticas e trofozoíticas de protozoários e ovos e larvas de helmintos (Pessoa, 1972).

\section{TESTE DE SUSCEPTIBILIDADE A DROGAS}

As bacterias enteropatogênicas iscladas foram submetidas ao teste de susceptibilidade a drogas pelo método do disco descrito por Bauer et al. (1966). Foram utilizadas as seguintes d́rogas: Ampicilina $(10 \mathrm{mcg}), \mathrm{Ac}$. Nalidixo $(30 \mathrm{mcg})$, Canamicina $(30 \mathrm{mcg})$, Carbenicilina $(100 \mathrm{mcg})$, Cioranfenicol $(30 \mathrm{mcg})$. Estreptomicina $(10 \mathrm{mcg})$, gentamicina $(10 \mathrm{mcg})$, Neomicina $(30 \mathrm{mcg})$, Nitrofurantoina (300 U.), Novobiocina $(30 \mathrm{mcg})$, Polimixina $(300 \mathrm{U}$.$) e$ Tetraciclina $(30 \mathrm{mcg})$. Todas as drogas utilizadas eram provenientes da SENSIBIODISC CECON (São Paulo, Brasii) .

\section{RESUltados}

Foram estudadas 110 crianças com quadro clínico de diarréia aguda atendidas em dois hospitais, de Tucuruí. Todas as amostras fecais foram examinadas para estudos bacteriológicos e parasitológicos 
A Tabela I mostra o número e as porcentagens das infecções Bacterianas, Parasitárias e Bacterians e Parasitárias de todos os casos de gastrenterites estudados.

A Tabela II evidencia a distribuição por faixa etária e sexo dos episódios diarreicos os números e as porcentagens dos agentes etiológicos bacterianos identificados.

A Tabela ill também fáz uma distribuição por faixa etária e sexo das infestações parasitárias nos 110 episódios diarreicos e respectivas porcentagens.

A Tabela IV apresenta os parasitas intestinais encontrados nos 110 casos de crianças diarreicas, número e respectivas porcentagens.

$\mathrm{Na}$ Tabela $\mathrm{V}$ verifica-se o comportamento das bactérias enteropatogênicas quando do tes. te de susceptibilidade a agentes antimicrobianos.

TABELA 1 - Números e porcentagens das infecções bacterianas, parasitárias e bacteriana e parasitária, dos 110 casos de diarréias agudas estudiados

\begin{tabular}{|c|c|c|c|c|c|}
\hline \multicolumn{2}{|c|}{$\begin{array}{l}\text { Infecções } \\
\text { Bacterianas }\end{array}$} & \multicolumn{2}{|c|}{$\begin{array}{c}\text { Infecçōes } \\
\text { Parasitárias }\end{array}$} & \multicolumn{2}{|c|}{$\begin{array}{l}\text { Infecções } \\
\text { Mistas }\end{array}$} \\
\hline $\mathrm{N}: 0$ & $\%$ & N. ${ }^{\circ}$ & $\%$ & N. & $\%$ \\
\hline 17 & 15,4 & 28 & 25,4 & 6 & 5,4 \\
\hline
\end{tabular}

Dentre as 23 cepas enteropatogênicas isoladas, somente uma (Escherichia coli 0119:K69) não apresentou resistência multipla frente às drogas antimicrobianas utilizadas. Uma cepa (E. coli 086a:K61) foi resistente a 11 drogas, duas (E. coli $026: \mathrm{K} 60$ ) a 10 drogas, três resistentes (duas E. coli 086a:K61 e uma E. coli 055:K59) a 9 drogas, seis resistentes (três $E$. coli 026: $\mathrm{K} 60$, uma $E$. coli $0111: \mathrm{K} 58$ a duas $E$. coli 086a: K61) a 8 drogas, quatro resistentes ( $E$. coli 0124:K72, E. coli 026:K60, E. coli 0127a:K63 e E. coli 055:K59) a 7 drogas, três resistentes (Shigella sonnei, E. coli 0124:K60 e E. coli 0111ab, 0111ac) a 6 drogas, duas resistentes (Shigella flexneri e E. coli 0125:K70) a 4 drogas e uma resistente (E. coli $026: \mathrm{K} 60$ ) a 3 drogas antimicrobianas.

A cepa de $S$. sonnei foi resistente à Ampicilina, Carbenicilina, Cloranfenicol, Entreptomicina, Novobiocira e Tetraciclina, enquanto a cepa de $S$. flexneri foi resistente a Ampicilina, Carbenicilina, Novobiocina e Tetraciclina.

Pela Tabela VI verificamos o modelo de resistência ou de sensibilidade dos enteropatogenos isolados. A cepa $E$. coli $026: \mathrm{K} 60$ de maior porcentagem de isolamento, $30,4 \%$, apresentou-se de uma maneira geral com sensibilidade a apenas a Gentamicina. Enquanto a cepa $E$. coli 086a:K61 de segunda maior porcentagem de isolamento $21,7 \%$ mostrou-se insensivel aos 12 antimicrobianos testados.

TABELA II - Distribuiçăo por faixa etária e sexo dos 110 episódios diarréicos, número e respectivas porcentagens das bactérias enteropatogênicas isoladas

\begin{tabular}{|c|c|c|c|c|c|c|c|c|c|}
\hline \multirow{2}{*}{$\begin{array}{l}\text { IDADE } \\
\text { (Anos) }\end{array}$} & \multirow{2}{*}{$\begin{array}{l}\mathrm{N}: \text { de } \\
\text { Casos }\end{array}$} & \multirow{2}{*}{8} & \multirow{2}{*}{ 우 } & \multicolumn{4}{|c|}{ LOCALIDADE } & \multicolumn{2}{|c|}{ POSITIVIDADE } \\
\hline & & & & Tu. & VT. & VP. & Outros & $\mathrm{N}:$ & $\%$ \\
\hline $0 \longrightarrow 1$ & 45 & 23 & 22 & 7 & 37 & 1 & 0 & 8 & 17,7 \\
\hline $1 \longrightarrow 2$ & 36 & 21 & 15 & 12 & 22 & 1 & 1 & 8 & 22,2 \\
\hline $2-3$ & 8 & 5 & 3 & 4 & 3 & 1 & 0 & 1 & 12,5 \\
\hline $3-4$ & 5 & 5 & 0 & 5 & 0 & 0 & 0 & 0 & 00,0 \\
\hline $4-5$ & 7 & 4 & 3 & 1 & 5 & 0 & 1 & 3 & 42,8 \\
\hline $5 \geqslant$ & 9 & 5 & 4 & 0 & 9 & 0 & 0 & 3 & 33,3 \\
\hline TOTAL & 110 & 63 & 47 & 29 & 76 & 3 & 2 & 23 & 20,9 \\
\hline
\end{tabular}

Tu, = Cidade de Tucurui

VT. = Vila Temporária

VP. $=$ Vila Permanente

Outros $=$ Arredores (estradas, etc.) 
TABELA III - Distribuição por faixa etária e sexo das infestaçōes parasitárias nos 110 episćdios diarréicos e respectivas porcentagens

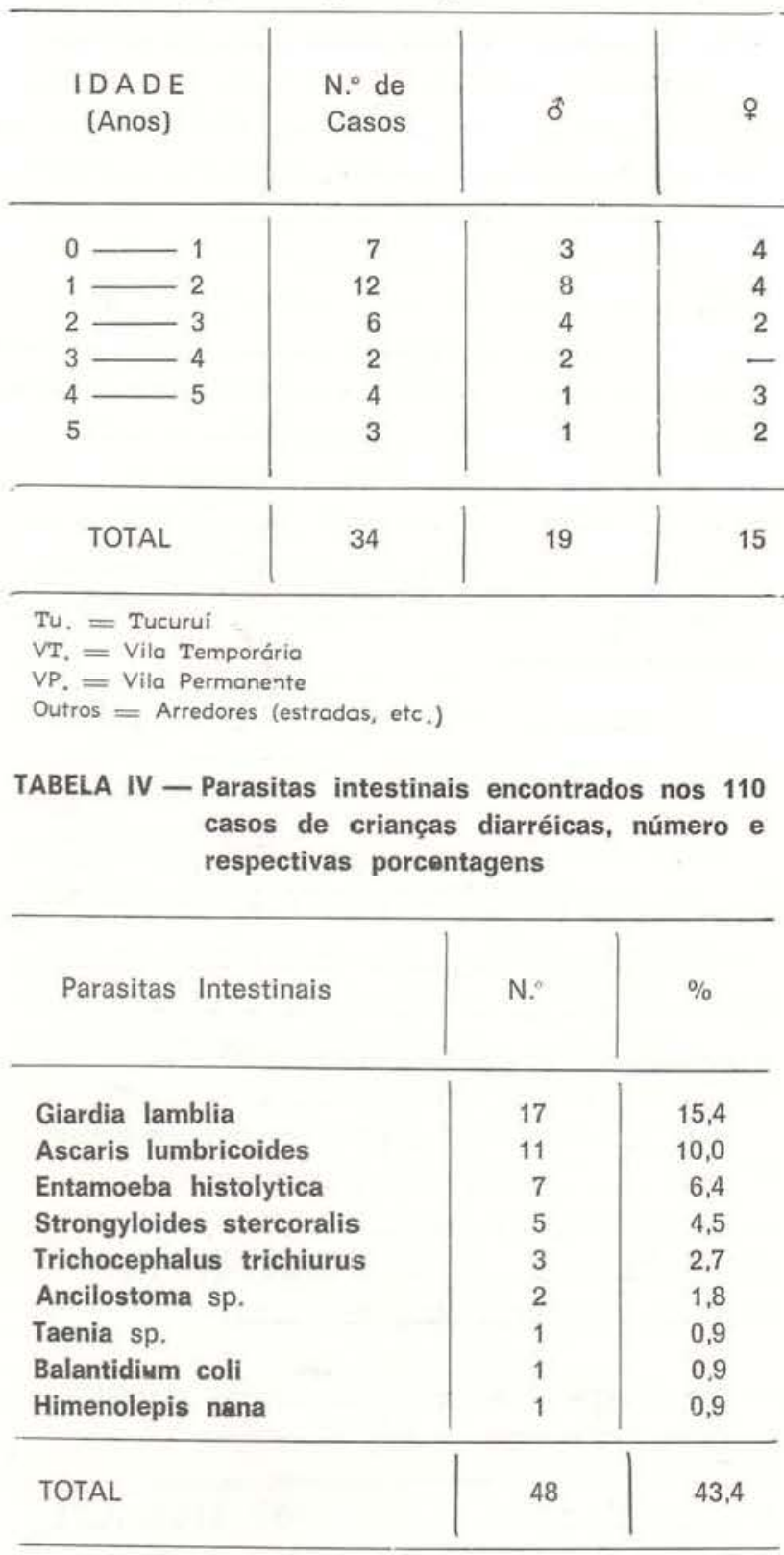

\section{Discussão E CONCLUSÕES}

A doença diarreica continua sendo a maior causa de morbidade e mortalidade em crianças, principalmente de pouca idade, nos países subdesenvolvidos e em desenvolvimento.

Neste estudo nos propusemos a determinar os agentes etiológicos das diarréias agudas em crianças na cidade de Tucuruí, Estado do Pará, sendo um dos primeiros, senão o primeiro, trabalho realizado neste sentido naquela localidade.

Foram examinadas 110 crianças com episódios de diarréia aguda atendidas por pediatras de 2 hospitais daquela localidade e seus materiais fecais analisados antes de qualquer tratamento médico, o que certamente viria influenciar na veracidade dos resultados.

Verifica-se através da Tabela II que a maior incidência de diarréia foi em crianças na faixa etária de 0 a 1 ano de idade o que vem concordar com os achados de outros autores em várias localidades brasileiras (Giugliano et al., 1977; Puffer \& Serrano, 1974; e Pessoa et al., 1978) .

A maior incidência de diarréia em criançass nos primeiros meses de vida vem evidenciar 0 pouco ou ausente aleitamento materno que daria uma grande proteção a estas crianças contra infecções, entéricas principalmente, conforme trabalhos de (Mellander et al., 1959; Mata \& Wyatt, 1971; Béhar, 1976; e Giugliano et al., 1977).

Em 51 casos $(46,2 \%)$ foram identificados; Bactérias e/ou Parasitas intestinais conforme mostra a Tabela I, sendo 17 casos $(15,4 \%)$ Bactérias, 28 casos $(25,4 \%)$ Parasitas 6 casos $(5,4 \%)$ Bactérias e Parasitas.

Pelo estudo bacteriológíco, na Tabela II, de todos os 110 casos diarreicos estudados, somente $23(20,9 \%)$ teve a sua etiologia bac- 
teriana determinada. Estes resultados vêm concordar com (Sack et al., 1975) que acham que somente em $20 \%$ a $40 \%$ os agentes etiológicos bacterianos são ideritificados utilizando-se coproculturas. Entretanto, em estudos posteriores será efetuada uma pesquisa com todas as cepas de Escherichia coli isoladas, no sentido de pesquisar enterotoxinas; termolábil (LT) e/ou termoestável (ST), além de teste de invasibilidade. Daí, então poderemos evidenciar uma maior porcentagem de patogenos bacterianos, pois, segundo Guerrant et al. (1975), a etiologia das diarréias poderá ser exclarecida em maior número quando se estuda as bactérias isoladas quanto à capacidade de produzir enterotoxinas e invasora. Somando a estes estudos, todas as amostras de fezes foram congeladas para pesquisa de rotavírus, que tem sido apontado por vários autores como causadores de gastrenterites, principalmente em crianças (Bishop et al., 1974; Candeias et al., 1978).

Através de exame parasitológico (Tabelas III e IV) foram identificados nove tipos diferentes de parasitas intestinais. Entretanto, segundo alguns autores (John et al., 1971), os parasitas intestinais deveriam ser melhor estudados, pois, parecem não ter uma grande significação como causa de diarréia. De qualquer modo estes resultados vêm mostrar uma elevada contaminação ambiental, principalmente pelo fato de que, conforme a Tabela III, nas faixas etárias de 0 a 1 e 1 a 2 anos, períodos em que se tem maiores cuidados de higiene com os filhos, estes apresentaram $20,5 \%$ e $35,2 \%$, respectivamente, de infestação parasitária.

Das amostras de fezes foram isoladas 8 diferentes sorogrupos de Escherichia coli e apenas 2 cepas de Shigella; Shigella sonnei e Shigella flexneri (Tabela V). Estes achados concordam com os de outros autores em várias localidades, que verificaram uma maior incidência de colibacilos patogênicos em: São Paulo (Pessoa et al., 1978); Manaus (Giugliano, et al., 1977); San Salvador, El Salvador (Bloch, 1975); Cali, Colômbia (Newell et al.. 1976).

Em trabalho realizado em Manaus (Giugliano et al., 1977), não houve prevalência entre os sorogrupos de E. coli isolados. Estudos efetuados em Belém (Lins, 1976) os sorogrupos mais encontrados foram 0119:B4 em 1971 e 1979 e 0111:B4 em 1973. Em trabalhos desenvolvidos em São Paulo no septênio 1970-76 (Pessoa et al., 1978) encontraram uma maior incidência de $E$. coli 0111:B4. No nosso estudo encontramos uma maior prevalência do sorogrupo 026:K60 e 086a:K61. O primeiro também foi o mais freqüente sorogrupo isolado em outras localidades (Newell et al., 1976; Nadkarm \& Lawande, 1974).

As cepas enteropatogênicas isoladas, submetidas a testes de susceptibilidade a drogas antimicrobianas, apresentaram os resultados conforme as Tabelas $\mathrm{V}$ e VI.

O uso descontrolado e excessivo de drogas levará sempre as condições de cepas resistentes a estas drogas. Na Tabela V e VI poderemos observar que a cepa 086a:K61 praticamente se apresentou resistente a todos os antimicrobianos utilizados e isto leva-nos a acreditar que anteriormente a mesma era o agente bacteriano de maior freqüência de isolamento. Essas cepas isoladas, altamente resistentes, são aquelas que conseguiram através de uma seleção, resistir às drogas usadas abusivamente por parte da população. Mesmo a cepa 026:K60 de maior porcentagem de isolamento, já se apresenta quase que totalmente resistente às drogas no estudo, evidenciando a necessidade de um tratamento correto, através de: primeiramente o isolamento do agente etiológico responsável pela infecção, e segundo, a indicação racional do antimicrobiano após um teste de sensibilidade a drogas. Isto se faz necessário porque segundo (Montelli et al., 1980) para que uma terapêutica seja eficaz, é imprescindível a determinação do agente etiológico correto da infecção, uma vez que poucas sāo as situaçōes em que o diagnóstico clínico pode ser suficiente para a escolha do antimicrobiano a utilizar-se.

\section{AgradeCimentos}

Expressamos os nossos agradecimentos ao corpo pediátrico dos Hospitais: da Camargo 
TABELA V - Enteropatogenos, número e suas respectivas porcentagens de resistência e diferentes drogas antificrobianas

\begin{tabular}{|c|c|c|c|c|c|c|c|c|c|c|c|c|c|c|c|c|c|c|c|c|c|c|}
\hline & \multicolumn{2}{|c|}{$\begin{array}{c}\text { E. coli } \\
\text { 0127:K63 }\end{array}$} & \multicolumn{2}{|c|}{$\begin{array}{c}\text { E. coli } \\
026: K 60\end{array}$} & \multicolumn{2}{|c|}{$\begin{array}{c}\text { E. coli } \\
086: K 61\end{array}$} & \multicolumn{2}{|c|}{$\begin{array}{c}\text { E. coli } \\
055: \mathrm{K} 59\end{array}$} & \multicolumn{2}{|c|}{$\begin{array}{c}\text { E. coli } \\
0124: K 72\end{array}$} & \multicolumn{2}{|c|}{$\begin{array}{c}\text { E. coli } \\
\text { 0111: K58 }\end{array}$} & \multicolumn{2}{|c|}{$\begin{array}{c}\text { E. coli } \\
\text { 0119:K69 }\end{array}$} & \multicolumn{2}{|c|}{$\begin{array}{c}\text { E. coli } \\
0125: K 70\end{array}$} & \multicolumn{2}{|c|}{$\begin{array}{c}\text { Shigella } \\
\text { sonnei }\end{array}$} & \multicolumn{2}{|c|}{$\begin{array}{l}\text { Shigella } \\
\text { flexneri }\end{array}$} & \multicolumn{2}{|c|}{ TOTAL } \\
\hline & $\mathrm{N}:$ & $\%$ & $\mathrm{~N}:$ & & $\mathrm{N}$ : & & N. ${ }^{\circ}$ & & N. & $\%$ & $\mathrm{~N}:$ & $\%$ & $\mathrm{~N}$ : & $\%$ & $\mathrm{~N} .^{\circ}$ & $\%$ & $N:$ & $\%$ & N. & $\%$ & & \\
\hline Ac. Nalidixo & - & - & 3 & 42,85 & 1 & 20 & - & - & - & - & - & - & - & - & - & - & - & - & - & - & 4 & 17,3 \\
\hline Ampicilina & - & - & 6 & 85,71 & 5 & 100 & 2 & 100 & 2 & 100 & 2 & 100 & - & - & 1 & 100 & 1 & 100 & 1 & 100 & 20 & 86,9 \\
\hline Canamicina & 1 & 100 & 4 & 57,14 & 5 & 100 & 2 & 100 & - & 一 & 1 & 50 & - & - & - & - & - & - & - & - & 13 & 56,5 \\
\hline Carbenicilina & 1 & 100 & 7 & 100 & 5 & 100 & 2 & 100 & 2 & 100 & 2 & 100 & - & - & 1 & 100 & 1 & 100 & 1 & 100 & 22 & 95,6 \\
\hline Cloranfenicol & 1 & 100 & 6 & 85,71 & 5 & 100 & 2 & 100 & 2 & 100 & 2 & 100 & - & - & - & - & 1 & 100 & - & - & 19 & 82,6 \\
\hline Estreptomicina & 1 & 100 & 6 & 85,71 & 5 & 100 & 1 & 50 & 2 & 100 & 2 & 100 & - & - & - & - & 1 & 100 & - & - & 18 & 78,2 \\
\hline Gentamicina & - & - & - & - & 2 & 40 & - & - & - & - & - & - & - & - & - & - & - & 一 & - & - & 2 & 8,6 \\
\hline Neomicina & 1 & 100 & 5 & 71,42 & 5 & 100 & 2 & 100 & - & - & 7 & 50 & - & - & - & - & - & - & - & - & 20 & 86,9 \\
\hline Nitrofurantoina & - & - & 2 & 28,57 & 1 & 20 & 1 & 50 & 1 & 50 & - & - & - & - & - & - & - & 一 & - & - & 5 & 21,7 \\
\hline Novobiocina & 1 & 100 & 7 & 100 & 5 & 100 & 2 & 100 & 2 & 100 & 2 & 100 & 1 & 100 & 1 & 100 & 1 & 100 & 1 & 100 & 23 & 100,0 \\
\hline Polimixina & - & - & 2 & 28,57 & 1 & 20 & - & - & - & - & - & - & - & - & - & - & - & - & - & - & 3 & 13,4 \\
\hline Tetraciclina & 1 & 100 & 6 & 85,71 & 5 & 100 & 2 & 100 & 2 & 100 & 2 & 100 & - & - & 1 & 100 & 1 & 100 & 1 & 100 & 21 & 91,3 \\
\hline
\end{tabular}


TABELA VI - Modelo de resistência dos enteropatogenos isolados

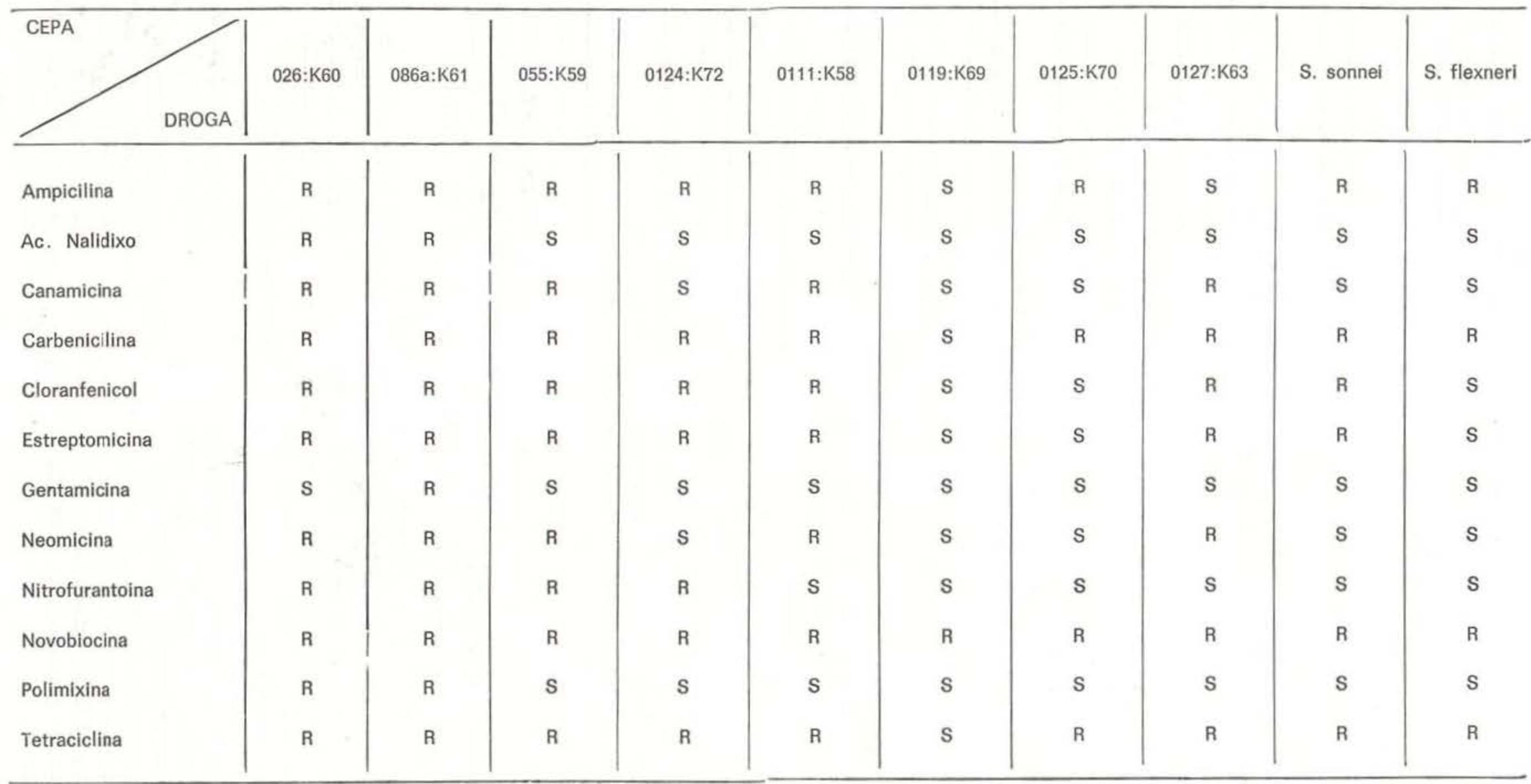

$\mathrm{R}=$ Resistente

$\mathrm{S}=$ Sensivel 
Correa e Secretaria Estadual de Saúde do Pará e ao pessoal técnico dos Laboratórios de Análises Clínicas dos dois hospitais, principalmente no exame parasitológico, sem os quais não teria sido possível o desenvolvimento deste trabälho.

Também agradecemos a SENSIBIODISC CECON (São Paulo) pela sua compreensão $e$ ajuda, cedendo muito gentilmente todos os discos utilizados no teste de susceptibilidade a drogas antimicrobianas.

\section{SUMMARY}

Bacteriological and Parasitological studies were carried out in the faces of 110 diarrhoeal children $0-10$ years old in two hospitals in Tucuruí, Estate of Pará, Brazil. The samples were examined before any medical treatment.

In 51 cases $(46,3 \%)$ Bacteria and/or Parasites were identified, being 17 cases $(15,4 \%)$ bacterias, 28 cases $(25,4 \%)$ intestinal parasites and 6 cases $(5,4 \%)$ mixed Bacteria and Parasites.

In 23 samples $(20,9 \%)$ Bacterial pathogens were isolated: 21 pathogenic Escherichia coli serogroup, 1 Shigella sonnei and 1 Shigella flexneri. Eight different E. coli serogroups were identified. The most frequent serogroup were firstly $026: \mathrm{K} 60$ and secondly $086 \mathrm{a}: \mathrm{K} 61$. All pathogenic strains except E. coli 0119:K69 showed multiple resistance to 12 antimicrobial drugs.

The intestinal parasites identified were: Giardia lamblia $15,4 \%$, Ascaris lumbricoides $10,0 \%$, Entamoeba histolytica $6,3 \%$, Strongyloides stercoralis $4,5 \%$, Trichocephalus trichiurus $2,7 \%$, Ancilostoma sp. 1,8\%, Taenia sp. $0,5 \%$, Balantidium coli $0,9 \%$ and Himenolepis nana $0,9 \%$.

\section{REFERENCIAS BIBLIOGRÁFICAS}

BACK, E.H. \& BROOKS, S.E.H.

1962 - The pattern of infantile gastroenteritis in Jamaica. W. Indian Med. J., 11: 179-187.

BAUER, A.W.; KIRBY, W.M.M.; SHERRIS, J.C.; TURCK. M. 1966 - Antibiotic susceptibility testing by standardized single disk method. Am. J. Clin. Pathi, 45 (4): $493-496$.

BÉHAR, M.

1976 - Importância da alimentação e da nutrição na patogenia e prevenção dos processos diarréicos, In: Bolm. Epid. SESP, 8 (5): 41-51.

BISHOP, R.F.; DAVIDSON, G.P.; HOLMES, I.H.; RUCK, B.J. 1974 - Detection of a New virus by Electron Microscopy of faecal Extracts from children with Acute gastroenterites. LANCET., 1: 149-151.
$\mathrm{BLOCH}, \mathrm{M}$.

1975 - Infecciones por bacilos gram negativos: importancia de su estudio, Rev Inst. Invest. Med., 4 (2): 149-214.

CANDEIAS, J.A.N.; ROSENBURG, C.P.; RACZ, M.L.

1978 - Identificação por contraimunoeletroforese de Rotavirus em casos de diarréia infantil. Rev. Saúde. Públ., 12: 99-103.

DUPONT, H.L.

1975 - Estudios necesarios para enriquecer el conocimento de las infecciones entericas y reducir sus consecuencias en terminos de morbilidad y mortalidad. Bolm. Of. Sanit. Pan-Am., 78 (4): 346-349.

EDWARDS, P.R. \& EWING, W.H.

1975 - Identification of Enterobacteriaceae $3 \mathrm{rd}$ ed. Minneapolis Minnesota, U.S.A., 362p.

ELETRONORTE

1980 - Informativo sobre a Usina Hidrelétrica de Tucuruí. Ministério das Minas e Energia.

Estudios y estrategias necesarios para reducir la morbidad y la mortalidad por infecçōes entéricas.

1975 - Apud - In: Boin. Of. Sanit. Pan-Am., 78 (4): 281-291.

GIUGLIANO, L.G.; GIUGLIANO, R.; PINHEIRO, M.F.

1977 - Bactérias enteropatogênicas em lactentes de um bairro de Manaus - Amazonas. Acta Amazonica, 7 (3): 395-400.

GUERRANT, R.L.; MOORE, R.A.; KIRSCHENFELD, P.M.; SANDE, M.A.

1975 - Role of toxigenic and invasive bacteria in acute diarrhea of childhood, New. Engl. J. Med., 293 (12): 567-573.

JOHN, T.J.; MONTCOMORY, E.; JAYABAL, P.

1971 - The prevalence of intestinal parasitism and its relation to diarrhoea in children, Indian Pediat., 8: 137.

LINS, Z.C.

1976 - Patologia Tropical na Amazônia: recentes aquisiçōes In: Doenças Infecciosas e Parasitárias. 6 ed., Rio de Janeiro, Guanabara Koogan, p. 1053-1070.

MATA, L.J. \& WYATT, R.G.

1971 - Host resistance to infection In: Symposium, the iniqueness of human milk, Am. J. Clin. Nutr., 24, 976-986.

MELLANDER, C.; VOHLQUIST, B.; MELLBIN, T.

1959 - Breast feeding and artificial feeding clinical, sorological and biochemical study in 402 infants with a survey of the literature; the Norrbotten study, Acta Pediat., 48 SS 116, 1-108. 
MONTELLI, A.C.; TOLEDO, M.R.F.; SILVA, M.L.R.

1980 - Importância do diagnóstico etiológico das infecções e da sensibilidade dos agentes bacterianos às drogas. Informação da Soc. Bras. Microb.

NADKARNI, M.S. \& LAWANDE, R.V.

1974 - Enteropathogenic Escherichia coli and neo natal diarrhoea, Indian J. Med. Sci., 28 (10): 431-436.

NEWEL, K.W.; DOVER, A.S.; CLEMMER, D.I.;

D'ALESSANDRO, A.; DUEÑAS, A.; GRACIAN, M.; LEBLANC, D.R.

1976 - Las enfermidades diarreicas de la infancia en Cali, Colombia, Diseño e informe resu. mido de um estudio sobre los agentes pa. togenos aislados. Boln. Of. Sanit. Pan-Am., 81 (1): 28-43.

PESSOA, S.B.

1972 - Parasitologia Médica. Guanabara Koogan.
PESSOA, G.V.A.; CALZADA, C.T.; PEIXOTO, E.S.; MELLES. C.E.A.; KANO, E.; RASKIN, M.; SIMONSEN, V.; IRINO, K.

1978 - Ocorrência de bactérias enteropatogênicas em São Paulo no Septênio 1970-76. III Sorotipos de Shigella e de Escherichia coli da gastrenterite infantil. Rev. Inst. Adolfo Lutz. 38 (2): 129-139.

PUFFER, R.R. \& SERRANO, C.V.

1974 - Interrelacion de varios factores que intervienen en la mortalidad infantil, Boln. Of. Sanit. Pan-Am. 67 (6): 509-533.

SACK, R.B.

1975 - Human diarrheal disease caused by enterotoxigenic Escherichia coli. A. R. Micro. bial., 29: 333-353.

(Aceito para publicação em 15/05/81) 